galaxy of complications. Cytotoxic drugs have immediate side effects such as nausea and vomiting, phlebitis, alopecia, neuropathy, and late complications seen in the form of second malignancy some years after successful control of Hodgkin's disease. ${ }^{6}$ Several drugs, such as etoposide and methotrexate, are being advocated in first line treatment to lessen these effects, and several trials are attempting to find the minimum amount of chemotherapy compatible with the maximum response rate.

Radiotherapy is not without its problems either, particularly in children. Serious disturbance of growth and interference with the development of the endocrine and reproductive organs are of great concern in young patients-whose prognosis is better than that of adults. ' Furthermore, the addition of radiotherapy to chemotherapy further increases the risk of secondary malignancy in both child and adult. Not surprisingly, therefore, paediatricians have been experimenting with smaller radiotherapy fields and lower doses in children with limited disease.

An article describing long term survival of children treated for Hodgkin's disease in Britain appeared recently in the Archives of Disease in Childhood. ${ }^{8}$ The report spanned the period 1974-82 and included 80 children. The complete remission rate of these patients was $95 \%$ and their actuarial five year survival $94 \%$. The relapse free survival was $82 \%$, with a median follow up of $4 \cdot 8$ years. An encouraging feature of this report is the tendency to give chemotherapy to children with earlier stages of disease in order to avoid staging laparotomy and extended field radiation. The reduction in these fields and doses of $x$ rays prevented stunting of growth, hypothyroidism, and hypoplasia of breasts in pubertal girls. Substituting chlorambucil for nitrogen mustard lessened acute nausea and vomiting but it seems unlikely to prevent secondary tumours or disturbances of fertility. In the same vein the Amsterdam Working Party for Childhood Tumours treated nine patients in stages I and II with tumours smaller than $4 \mathrm{~cm}$ with six MOPP cycles without radiotherapy (H Behrendt, B Van Bunningen, paper given at second international conference on malignant lymphoma, Lugano, Switzerland, 1984). All are in sustained complete remission with a median follow up of five years. Nine further patients with larger tumours were given the same drugs, sandwiched round local radiation of $25 \mathrm{~Gy}(2500$ rads). Only one child relapsed (outside the irradiated area) after 26 months, and he died of progressive disease. The remainder are free of disease with a follow up of 22-72 (median 50) months. These two reports show how successful chemotherapy can be in children with very early stages of Hodgkin's disease. The omission of staging laparotomy is therefore logical, and radiotherapy may reasonably be reduced or omitted. Problems of potential overtreatment of patients remain, however, and efforts need to be continued to remove potential carcinogenic substances from chemotherapy regimens.

Despite the astonishing success of the past 21 years small groups of patients may be identified who will fare less well. Young girls with bulky mediastinal masses are one such group, and at the other end of the age range treatment in patients over 60 still has a $60 \%$ failure rate. New therapeutic regimens must be developed for these high risk patients, and further clinical trials of multidisciplinary treatment (now the accepted norm) are mandatory. Tackling Hodgkin's disease in such a fashion has paid rich dividends. The lessons of the past two decades have provided oncology with an excellent model which is now being successfully applied to other forms of solid tumour. We hope that the next 21 years will see the control with multimodality treatment of the "big three" cancers-breast, lung, and colon.

J G McVIE Clinical research coordinator

R SOMERS

The Netherlands Cancer Institute,

Consultant physician

Antoni van Leeuwenhoek Huis,

Amsterdam

Correspondence to : $\mathrm{Dr} \mathrm{J}$ G McVie.

1 DeVita VT, Moxley JH III, Brace K, Frei E III. Intensive combination chemotherapy and xirradiation in the treatment of Hodgkin's disease. Proceedings of the American Association for Cancer Research 1965;6:15.

2 DeVita VT, Canellos P, Moxley JH. A decade of combination chemotherapy of advanced Hodgkin's disease. Cancer 1972;30:1495-504.

3 Santoro A, Bonadonna G, Bonfante V, Valagussa P. Alternating drug combinations in the treatment of advanced Hodgkin's disease. $N$ Engl f Med 1982;307:770-5.

4 Tubiana $M$, Henry-Amar $M$, Hayat $M$, et al. Prognostic significance of the number of involved areas in the early stages of Hodgkin's disease. Cancer 1984;54:885-94.

5 Cooper E, Pajak TF, Gottlieb AJ, et al. The effects of prior radiation therapy and age on the frequency and duration of complete remission among various four-drug treatments for advanced frequency and duration of complete remission among various four-d

6 Tester WJ, Kinsella TJ, Waller B, et al. Second malignant neoplasms complicating Hodgkin's disease: the National Cancer Institutc experience. Foumal of Clinical Oncology 1984;2:762-9.

7 Mauch PM, Weinstein H, Notnick L, Belli J, Cassady JR. An evaluation of long-term survival and treatment complications in children with Hodgkin's disease. Cancer 1983;51:925-32.

8 Robinson B, Kingston J, Nogueira Costa R, Malpas JS, Barrett A, McElwain TJ. Treatment of childhood Hodgkin's disease with chlorambucil, vinblastine, procarbazine and prednisolone (ChIVPP), and irradiation to sites of initial bulk disease. Arch Dis Child 1984;59:1162-7.

\section{Cigar and pipe smoking and the heart}

Some facts about smoking are not disputed. Cigarette smoking is a major causative risk factor for coronary heart disease, at least in communities with relatively high serum cholesterol concentrations ${ }^{1}$; and stopping cigarette smoking substantially reduces the risk of coronary attacks in healthy people ${ }^{23}$ and in survivors of myocardial infarction. ${ }^{4}$ Much less is known, however, about the possible adverse effects of pipe and cigar smoking in the genesis of coronary heart disease, nor do we have much information about the effect, if any, of pipe and cigar smoking on subsequent morbidity and mortality in survivors of myocardial infarction.

Our ignorance has been highlighted by a recent article by Jarvis $e t a l$, in which they analysed the data on smoking from the Multiple Risk Factor Intervention Trial (MRFIT). ${ }^{56}$ They argued that the changes in smoking habits in the "intervention" group in that trial may have been overestimated because cigar and pipe smokers were classed as non-smokers, despite the evidence that such smokers had raised serum thiocyanate concentrations, suggesting that they had inhaled nicotine, carbon monoxide, and other tobacco products. Given that Jarvis $e t$ al are correct in their interpretation, these inaccurate survey data might account, in part at least, for the relatively small differences that were observed in morbidity and mortality between the intervention and control groups in the MRFIT trial.

Epidemiological and clinical studies of the effects of pipe and cigar smoking as coronary risk factors have been hampered by the relatively small number of people who are regular pipe and cigar smokers, and because-in contrast to cigarette smokers - their smoking habits vary widely in terms of the quantity smoked and the extent of inhalation. Some population studies have reported a much smaller relative risk in pipe and cigar smokers than in cigarette smokers. The Surgeon General of the United States found a marginally raised risk from 1.02 to 1.40 in four studies of pipe smokers and three of cigar smokers compared with a 
risk ratio of between 1.6 and $2 \cdot 5$ in cigarette smokers. ${ }^{1}$ In a Copenhagen study of 3772 smokers and 1440 non-smokers, however, the risk of fatal and non-fatal myocardial infarction combined was excessive for smokers and was no different for smokers of pipes, cigars, and cigarettes, with heavy smokers of cheroots at greatest risk. ${ }^{7}$ Auerbach and Garfinkel, in a necropsy study of 1412 men, found an increase in the extent and complexity of aortic atherosclerotic plaques in pipe and cigar smokers as well as cigarette smokers. ${ }^{8}$ In other reports no association could be found between pipe and cigar smoking and stroke ${ }^{9}$ or peripheral vascular disease. ${ }^{10}$ Little has been published about the influence of cigar and pipe smoking on mortality after myocardial infarction. Hickey et al found an increase in subsequent mortality of similar proportions in survivors who continued to smoke cigarettes and in those who smoked cigars but no increased mortality in pipe smokers. ${ }^{11}$

Several studies have shown that carboxyhaemoglobin concentrations and other markers of inhalation are raised in cigarette smokers who change to pipe or cigar smoking. ${ }^{12-15}$ So the smoking of pipe or cigar tobacco by ex-cigarette smokers after myocardial infarction probably increases their risk of further coronary episodes, though more secondary prevention studies are required to confirm this view.

What advice, then, should be given to cigarette smokers with overt coronary heart disease? Can they safely change to pipes or cigars? Evidence from primary and secondary prevention studies of coronary heart disease that cigar and pipe tobacco are independent risk factors is conflicting and is flimsy compared with the evidence on cigarette smoking. Nevertheless, complete abstention from tobacco is probably sound advice, at least in cigarette smokers and in those with overt coronary heart disease. Apart from suffering possible deleterious effects, survivors of myocardial infarction who continue to smoke a pipe or cigars, or who change to these forms of smoking, show a peristent dependency-which in my own clinical experience indicates less than satisfactory motivation and therefore a greater likelihood of recidivism. In encouraging cigarette smokers to stop the greatest effect is achieved by careful counselling by a dedicated and informed health professional. Full knowledge of the harmful effects of smoking and of the benefits of giving up, if adequately conveyed to the patient who is anxious to quit the habit, will frequently succeed in making him stop smoking completely. Recourse to alternatives, such as pipe or cigar smoking or nicotine chewing gum, must be regarded as second best.

\section{RISTEARD MULCAHY}

Professor of Preventive Cardiology,

St Vincent's Hospital, University College,

Dublin 4

1 Surgeon General. The health consequences of smoking. Cardiovascular disease. A report of the Surgeon General. Rockville, Maryland: US Department of Health and Human Services, Public Health Service, 1983.

2 Doll R, Peto R. Mortality in relation to smoking: 20 years' observations on male British doctors. BrMed f 1976;ii: 1525-36.

3 Enstrom JE. Trends in mortality among California physicians atter giving up smoking: 1950-79. BrMed f 1983;286:1101-5.

4 Mulcahy $R$. Influence of cigarette smoking on morbidity and mortality after myocardial infarction. Br Heart $\mathcal{F}$ 1983;49:410-5.

5 Jarvis $M$, West $R$, Tunstall-Pedoe $H$, Vesey $C$. An evaluation of the intervention against smoking in the Multiple Risk Factor Intervention Trial. Prev Med (in press)

6 Multiple Risk Factor Intervention Trial Research Group. Multiple Risk Factor Intervention Trial: risk factor changes and mortality results. $\mathcal{J} A M A$ 1982;248:1465-77.

7 Gyntelberg F, Lauridsen L, Pedersen PB, Schubell K. Smoking and risk of myocardial infarction in Copenhagen men aged 40-59 with special reference to cheroot smoking. Lancet 1981;i:987-9.

8 Auerbach $\mathrm{O}$, Garfinkel $\mathrm{L}$. Atherosclerosis and aneurysm of the aorta in relation to smoking habits and age. Chest 1980;78:805-9.

9 Rogot E, Murray JL. Smoking and causes of death among US veterans: sixteen years of observation. Public Health Rep 1980;95:213-22.

10 Feinleib M, Williams RR. Relative risks of myocardial infarction, cardiovascular disease and peripheral vascular disease by type of smoking. In: Wynder EL, Hoffman D, Gori GB, eds. Modifying the risk for the smoker. Vol 1. Proceedings of the third world conference on smoking and health, New York 1975. Washington: US Department of Health, Education, and Welfare, 1976:243-56. (DHEW Publication No (NIH) 76-1221.)
11 Hickey N, Mulcahy R, Daly L, Graham I, O'Donoghue S, Kennedy C. Cigar and pipe smoking related to four year survival of coronary patients. Br Heart $f$ 1983;49:423-6.

12 Castleden CM, Cole PZ. Inhalation of tobacco smoke by pipe and cigar smokers. Lance $1973 ; i: 21-4$.

13 Goldman AL. Carboxyhemoglobin levels in primary and secondary cigar and pipe smokers. Chest 1977;72:33-5.

14 Turner JAM, Sillett RW, McNichol MW. Effect of cigar smoking on carboxyhaemoglobin and plasma nicotine concentrations in primary pipe and cigar smokers and ex-cigarette smokers. $\mathrm{Br}$ Med f 1977;ii:1387-9.

15 Ronan G, Ruane P, Graham IM, Hickey N, Mulcahy R. The reliability of smoking history amongst survivors of myocardial infarction. Br $\mathcal{J}$ Addict 1981;76:425-8.

\section{Scots lead the way on alcohol}

After a four year gestation the Scottish Health Education Coordinating Committee has produced the most impressive plan of action yet seen in Britain on how to combat alcohol problems. ${ }^{1}$ The report recognises that this is a job not just for government or for doctors (as some politicians have suggested ${ }^{2}$ ) or any other single group but a job for everybody in Scotland. When they read this report politicians, doctors, civil servants, teachers, policemen, union leaders, broadcasters, and many other groups will all find that they have been allotted a role in reducing Scotland's alcohol problems.

The past 10 years have seen a plethora of reports on alcohol, but most have been concerned with describing the problems associated with alcohol rather than a plan for overcoming them..$^{3-10}$ The only report that came close to matching this present Scottish report in the scope of its suggestions was the suppressed report by the government's think tank (Central Policy Review Staff $).{ }^{6}$ The flimsy Department of Health and Social Security document Prevention and Health: Drinking Sensibly, which could be seen as the government substitute for the suppressed report, was much stronger on platitudes than suggestions. ${ }^{8}$

In 1980 the Scottish Health Service Planning Council gave high priority to prevention in its report Scottish Health Authorities' Priorities for the Eighties, and it rated preventing alcohol abuse as second only to preventing smoking related diseases." The Scottish Health Education Coordinating Committee adopted similar priorities and set up a core group under the chairmanship of Sir John Crofton to produce this plan of action. The plan was originally intended to be for health boards, local authorities, and voluntary bodies, but the committee was wise enough to expand the plan to cover other national groups. The boldness in expanding the remit of the committee and the forcefulness, clarity, and comprehensiveness of its conclusions are all, we suspect, attributable in large part to the work of Sir John, who is well known for his excellence in chairing committees.

The report begins with an outstanding review of how the Scots (and sometimes all of the British) drink and the problems they experience as a result. The often quoted statistic that alcohol consumption in Britain almost doubled between 1950 and 1980 is brought up to date with data that show that it fell between 1980 and 1982 and rose again only slightly in 1983. Pie diagrams illustrating what we drink show how the "wine slice" is increasing and the "beer slice" decreasing, although the latter still accounts for more than half of consumption. A very recent paper from the professor of psychiatry in Edinburgh shows that the $11 \%$ fall in consumption between 1979 and 1982 was followed by a $19 \%$ fall in first admissions for alcohol dependence, a $16 \%$ fall in drunkenness convictions, a $7 \%$ fall in drinking and driving convictions, and a $4 \%$ fall in deaths from cirrhosis. ${ }^{12}$

Problems associated with alcohol are then categorised in 